\title{
Effect of Solubilization Temperature, Zn Addition and Thermo-Mechanical Treatments in the Microstructure of the Aluminum 2024 Alloy
}

\author{
C.G. Garay-Reyes, L. González-Rodelas, I. Estrada-Guel and R. Martínez-Sánchez
}

Centro de Investigación en Materiales Avanzados (CIMAV) Miguel de Cervantes No. 120, 31109 , Chihuahua, Chih., México

\begin{abstract}
Al-2024 is a Cu-rich heat treatable alloy which is used in aerospace applications because of its high strength/weight ratio, as well good fatigue resistance [1]. Precipitation heat treatments are an important procedures that directly affects the mechanical properties of the material. An important step of such treatments is solubilization, where the main objective consist in maintain the maximum amount of solute phases in solid solution, where the processing time is a critical variable to control to obtain a satisfactory degree of solubilized [2]. The addition of $\mathrm{Zn}$ to the 2024 alloy has been investigated and reported by various authors, $\mathrm{Zn}$ and $\mathrm{Al}$ have a difference of $7 \%$ in the atomic radius [3], which represents some advantages from structural viewpoint due the mechanism of hardening by solid solution.
\end{abstract}

Studies on thermo-mechanical treatment of aluminum alloys start from 196Os [4, 5]. Thermo-mechanical treatments are divided into intermediate thermo-mechanical treatment (ITMT) and final thermo-mechanical treatment (FTMT) by Russo and coworkers [5]. ITMT involves high temperature, which focuses on grain morphologies refining, as-cast microstructures modification and depleting component segregation. FTMT includes low temperature age hardening by deformation and precipitation.

The aim of this work is to evaluate the effect of solubilization temperature, $\mathrm{Zn}$ addition and thermo-mechanical treatments on the Al-2024 alloy. The alloy fabrication with Zn additions (0.25 to 0.75 wt. \%) was made by conventional direct casting, the melt was degassed with argon gas (20 PSIg) for 5 min period and AlTiB was added as grain refiner ( $0.13 \%$ weight $)$.

$\mathrm{Zn}$ modification was performed with the addition of a $\mathrm{ZnAl}$ master alloy (Zn72.7-A127-Cu0.2 Mg-0.1), commercially known as ZA27. The ITMT treatment consisted in hot rolling at $490^{\circ} \mathrm{C}, 50 \%$ of thickness reduction and solubilization $\left(495^{\circ} \mathrm{C}\right)$ with different times. The FTMT treatment involved 5 to $10 \%$ thickness reduction by cold rolling and a final aging step $\left(195^{\circ} \mathrm{C}\right)$ at several times. The microstructural characterization was done using an optical microscope ZEISS model Scope A1 and a SEM JEOL model JSM 5800-LV

The Fig. 1 shows representative images of 2024-0.25 Zn alloy after heat treatment of solubilization for different times. It can be seen as decrease segregation of solute in the interdendritic region in function of time of solubilized. The Fig. 2 shows representative images of Al-2024 alloy with different additions of $\mathrm{Zn}$ after ITMT processing. It is noticeable the thermo-mechanical treatment effect on the casting structure: as randomly oriented grains with identical properties in all directions (isotropy). However, after hot rolling, grains are textured and the properties change at different directions (anisotropy). It is worth mentioning that we are working to complete the characterization for all conditions via SEM and TEM. 


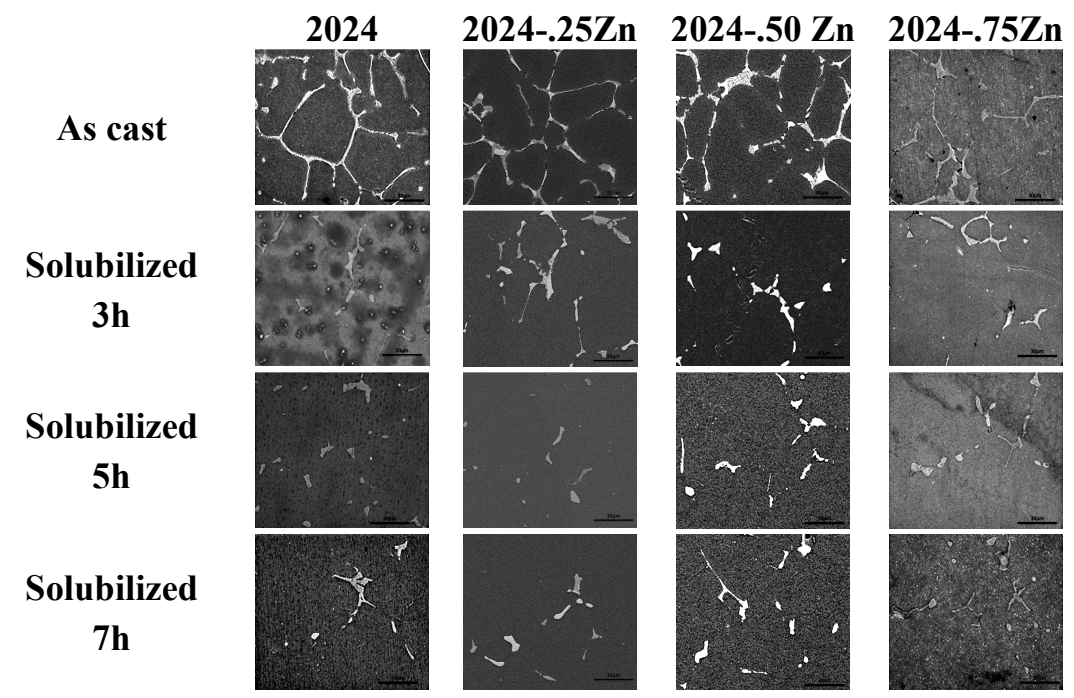

Fig. 1. SEM micrographics of Al-2024 alloy with different times of solubilized.

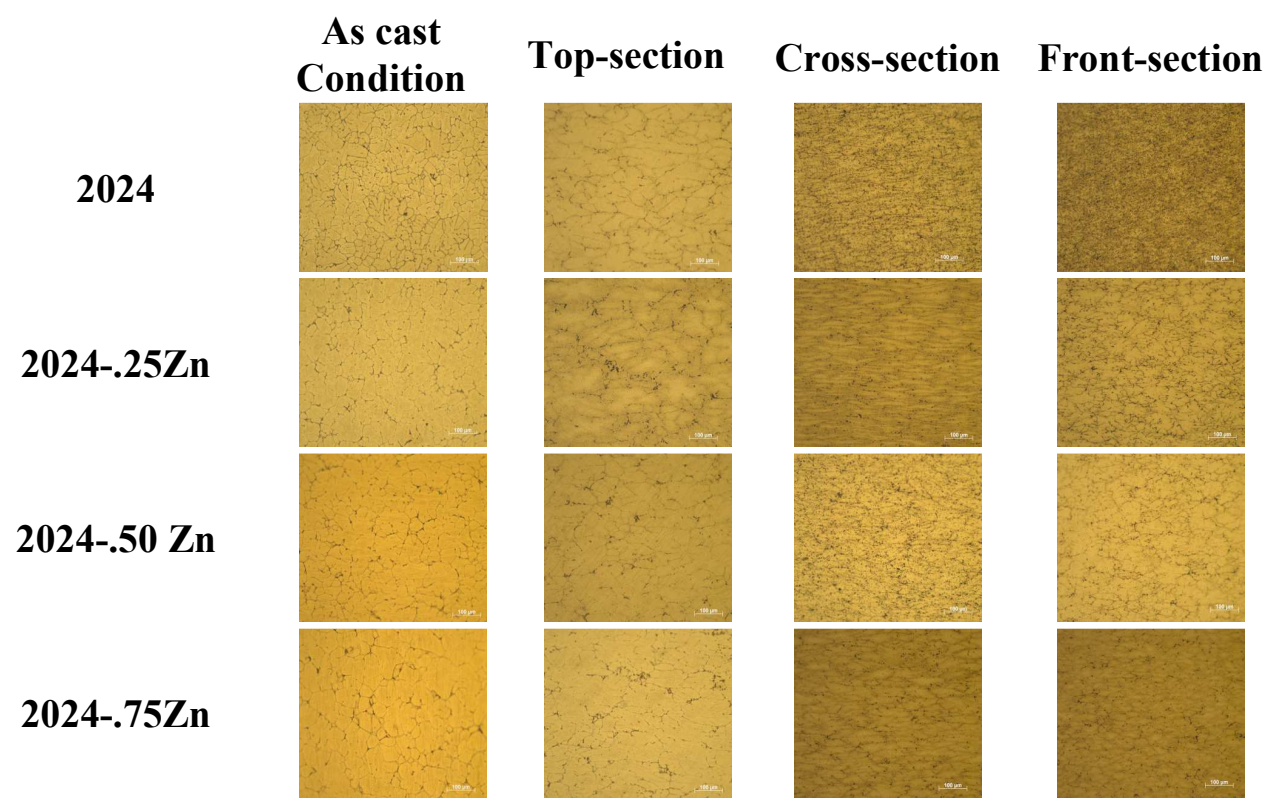

Fig. 2. Optical micrographics of 50\% hot rolled Al-2024 alloy with different additions of Zn.

\section{References}

[1] Y.C. Lin, Y. Xia, Y. Jiang, H. Zhou and L. Li, Mat. Sci. Eng. A 565 (2013) p. 420-429.

[2] A.J. Ardell, Metall Trans A 16 (1985) p. 2131-2162.

[3] Ž. Skoko, S. Popović and G. Štefanić, Croatica Chemica Acta 82 (2009) p. 405-420.

[4] W.E. Duckworth, JOM, 1 (1966) p. 915-922.

[5] A.J. Mcevily, J.B. Clark, A.P. Bond, ASM Trans 60 (1967) p. 661-671.

[6] E.D. Russo, M. Conserva, F. Galto, H. Mafxus, Metall Trans 4-4 (1973) p. 1133-1144. 